PREPARED FOR THE U.S. DEPARTMENT OF ENERGY, UNDER CONTRACT DE-AC02-76CH03073

PPPL-3787

PPPL-3787

UC-70

Secondary Electron Emission from Dielectric Materials of a Hall Thruster with Segmented Electrodes

by

A. Dunaevsky, Y. Raitses, and N.J. Fisch

February 2003

$=$ PPPL

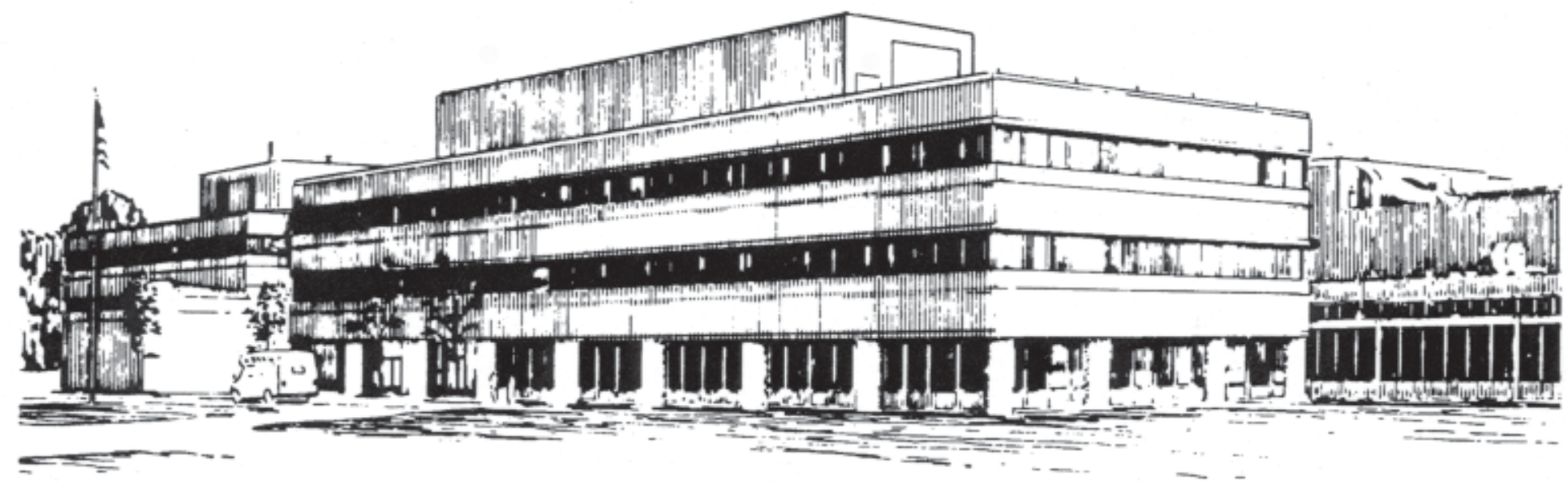

PRINCETON PLASMA PHYSICS LABORATORY PRINCETON UNIVERSITY, PRINCETON, NEW JERSEY 


\section{PPPL Reports Disclaimer}

This report was prepared as an account of work sponsored by an agency of the United States Government. Neither the United States Government nor any agency thereof, nor any of their employees, makes any warranty, express or implied, or assumes any legal liability or responsibility for the accuracy, completeness, or usefulness of any information, apparatus, product, or process disclosed, or represents that its use would not infringe privately owned rights. Reference herein to any specific commercial product, process, or service by trade name, trademark, manufacturer, or otherwise, does not necessarily constitute or imply its endorsement, recommendation, or favoring by the United States Government or any agency thereof. The views and opinions of authors expressed herein do not necessarily state or reflect those of the United States Government or any agency thereof.

\section{Availability}

This report is posted on the U.S. Department of Energy's Princeton Plasma Physics Laboratory Publications and Reports web site in Fiscal Year 2003. The home page for PPPL Reports and Publications is: http://www.pppl.gov/pub_report/

DOE and DOE Contractors can obtain copies of this report from:

U.S. Department of Energy

Office of Scientific and Technical Information

DOE Technical Information Services (DTIS)

P.O. Box 62

Oak Ridge, TN 37831

Telephone: (865) 576-8401

Fax: (865) 576-5728

Email: reports@adonis.osti.gov

This report is available to the general public from:

National Technical Information Service

U.S. Department of Commerce

5285 Port Royal Road

Springfield, VA 22161

Telephone: $1-800-553-6847$ or

(703) $605-6000$

Fax: (703) 321-8547

Internet: http://www.ntis.gov/ordering.htm 


\title{
Secondary Electron Emission from Dielectric Materials of a Hall Thruster with Segmented Electrodes
}

\author{
A. Dunaevsky, Y. Raitses, and N. J. Fisch \\ Plasma Physics Laboratory, Princeton University, P.O.Box 451, Princeton, NJ 09543, US
}

The discharge parameters in Hall thrusters depend strongly on the yield of secondary electron emission from channel walls. Comparative measurements of the yield of secondary electron emission at low energies of primary electrons were performed for several dielectric materials used in Hall thrusters with segmented electrodes. The measurements showed that at low energies of primary electrons the actual energetic dependencies of the total yield of secondary electron emission could differ from fits, which are usually used in theoretical models. The observed differences might be caused by electron backscattering, which is dominant at lower energies and depends strongly on surface properties. Fits based on power or linear laws are relevant at higher energies of primary electrons, where the bulk material properties play a decisive role.

52.40.Hf, 79.20.Hx 


\section{INTRODUCTION}

Plasma-wall interaction is one of the key processes in physics of Hall thrusters. The material of the channel wall determines the difference between so-called stationary plasma thrusters (SPT), where the channel is made of dielectric ceramics, and thrusters with anode layer (TAL) with metal channel walls. ${ }^{1}$ Higher secondary electron emission (SEE) from ceramic walls in SPTs might be a reason for lower electron temperature and longer acceleration region compared to ALTs. ${ }^{2}$ According to the model of SPT suggested by Ahedo, the potential drops on the both inner and outer sheath and presheath, and, as a result, the electron losses on the channel walls, depend strongly on the yield of SEE. ${ }^{3}$ The distribution of the electron temperature along the SPT channel is also affected by SEE. In numerical simulations by Keidar et al., a change in the SEE coefficient from 0.95 to 0.8 leads to an increase of the peak value of $T_{e}$ from 16 to $30 \mathrm{eV}^{4}$ Effect of the electron backflow parameters on the sheath potential was also studied kinetically by Jolivet and Roussel. $^{5}$

The use of materials with different SEE to control both the potential profile in an SPT, and thereby the efficiency, has been explored theoretically $y^{6,7}$ and experimentally. 8,9,10,11 Segmented electrodes made of a material with different secondary emission properties have been shown to affect the potential distribution in the SPT channel, which, in turn, might cause the observed $20 \%$ reduction of the plasma plume divergence. ${ }^{9,10,11}$ Thus, it is of great importance to describe precisely SEE in the transition region between a wall and neutral plasma. 
This paper is organized as follows: in Section II, we are reviewing on how SEE is taken into account in existing models of plasma sheath in Hall thrusters, in Section III we are presenting our experimental setup for measurements of the total SEE yield from dielectric materials induced by low energy electrons, and in Section IV we are discussing the results of SEE measurements from boron nitride, quartz, and macor.

\section{REVIEW OF THE ROLE OF SEE IN PLASMA SHEATH}

The role of electron emission from the wall on the sheath potential was shown in the original work of Hobbs and Wesson. ${ }^{12}$ Assuming a Boltzmann distribution for plasma electrons, the potential drop on the sheath in presence of secondary electron emission could be expressed as

$$
\varphi=k T_{e} \ln \left(\frac{1-\sigma\left(T_{e}\right)}{V_{0} \sqrt{2 \pi m_{e} / k T_{e}}}\right)
$$

Here $\sigma\left(T_{e}\right)$ is the total yield of secondary electron emission at the plasma electron temperature $T_{e}$, defined as a ratio of secondary emission flux to the primary flux. The model of Hobbs and Wesson does not consider the plasma-sheath transition and assumes that the velocity at the sheath edge, $V_{0}$, is equal to the Bohm velocity. In modern models of SPT, ${ }^{3,4}$ the actual radial velocity at the sheath edge is considered different from the Bohm velocity and is calculated from presheath models in the presence of the SEE flux.

The dependence $\sigma\left(T_{e}\right)$ is usually derived by averaging of the dependence of $\sigma\left(E_{p}\right)$ on the energy of the primary electrons, $E_{p}$, over Maxwellian distribution of $E_{p}$. At present, however, there is no systematic data for $\sigma\left(E_{p}\right)$ at $10<E_{p} \leq 100 \mathrm{eV}$ for most modern ceramics and dielectric materials. Existing theories of $\mathrm{SEE}^{13,14}$ are able to predict 
the behavior of $\sigma\left(E_{p}\right)$ analytically only at $E_{p}>80-100 \mathrm{eV}$. Therefore, the yield of SEE in SPT models is usually determined from various fits. Ahedo ${ }^{3}$ and Jolivet and Roussel ${ }^{5}$ used power law to fit the slope $\sigma\left(E_{p}\right)$ as

$$
\sigma\left(E_{p}\right)=\left(\frac{E_{p}}{E_{1}}\right)^{\alpha}
$$

where $E_{1}$ corresponds to $\sigma=1$. The average over the Maxwellian distribution yields ${ }^{5}$

$$
\left\langle\sigma\left(E_{p}\right)\right\rangle=\left\langle E_{p}\right\rangle^{\alpha} \Gamma(2+\alpha)\left(2 \mathrm{E}_{1}\right)^{-\alpha}=\left\langle E_{p}\right\rangle^{\alpha} \Gamma(2+\alpha) b .
$$

The same fit was used by Choueiri with $b=0.141$ and $\alpha=0.567$ for boron nitride. ${ }^{2}$

The fit of $\sigma\left(E_{p}\right)$ based on a power law assumes the monotonic decrease of the total SEE yield to zero with the decrease of $E_{p}$. The same nature of $\sigma\left(E_{p}\right)$ is conjectured by the majority of authors who deal with interactions of low temperature plasmas with dielectric walls. However, the contribution of backscattered electrons in the total backflow grows with the decrease of $E_{p}$. Consequently, the behavior of $\sigma\left(E_{p}\right)$ from dielectric materials should be more complicated in the low energy region, as it follows from our measurement presented below.

\section{EXPERIMENTAL SETUP}

Direct measurements of the yield of SEE at low energies of primary electrons are difficult because of the charging of the sample surface. Indeed, the surface will acquire a positive charge if the flux of secondary electrons is higher than primary flux, and negative in the opposite case. The electric field of the surface charge changes the energy of primary electrons. This electric field may also impede or facilitate the yield of low 
energy "true" secondary electrons. The uncertainty in measurements induced by surface charging should reach several times. ${ }^{15}$

In order to minimize the influence of the surface charging, the primary electron beam can be modulated by short pulses, as it was proposed in earlier works by Heydt ${ }^{16}$ and Johnson. ${ }^{15}$ The amplitude of the primary current and the duration of the current pulse should be short in order to minimize the surface charging. The total current in the sample circuit, $I_{s}$, can be expressed as ${ }^{17}$

$$
I_{s}=C \frac{d \varphi_{s}}{d t}+I_{c},
$$

where $I_{c}$ is the leakage current due to surface conductivity, $\varphi_{s}$ is the surface potential, and $C$ is the sample capacitance. Assuming $I_{c}=0$, that is correct for the most dielectric materials with low surface conductivity, the surface potential will increase linearly along with the current pulse of the primary electron beam

$$
\varphi_{s}=\frac{I_{P} d}{\varepsilon \varepsilon_{0} \pi r^{2}} t
$$

Here $d$ and $\varepsilon$ are the sample thickness and the dielectric constant, and $r$ is the radius of the beam focal spot. At the lowest energies of primary electrons, the total SEE yield is usually less then unity. Therefore, one should consider the maximal charging current $I_{s} \sim$ $I_{p}$. Assuming $\mathcal{E} \sim 2, d=0.3 \mathrm{~mm}, I_{p}=50 \mathrm{nA}$, and $r=0.5 \mathrm{~mm}$, the surface voltage should reach $\varphi_{s} \approx-1 \mathrm{~V}$ in $1 \mu \mathrm{s}$. Thus, at $E_{p} \sim 10 \mathrm{eV}$ the pulse duration of the primary electron beam is limited at $t<1 \mu \mathrm{s}$ by the desired uncertainty of the energy of primary electrons $\leq$ $10 \%$. Oppositely, at total SEE yield higher than 2, which realizes at energies of primary electrons of several tens of $\mathrm{eV}$ or higher, the charge of the surface is correspondently 
higher than $+1 \mathrm{~V}$. However, the surface potential remains less than $5 \%$ of the energy of incident electrons, and should be decreased by proper decrease of the beam current.

One can see that the surface potential can be decreased by the increase of the focal spot radius and by the decrease of the sample thickness. The decrease of $d$ will also lead to the increase of the time constant of the measuring circuit, $R C$, which is required to be higher than the pulse duration, and to decrease the influence of parasitic capacitances.

Our experimental setup is represented schematically in Fig. 1. The primary electron beam was generated by an electron gun ELG-2 produced by Kimball Physics, Inc. The range of electron energies was $6-1000 \mathrm{eV}$; the maximal beam current was 10 $\mathrm{mA}$. The minimal diameter of the beam focal spot was $1 \mathrm{~mm}$. The duration of the pulse can be set down to $100 \mathrm{~ns}$, which was set by an external 6040 pulse generator produced by Berkley Nucleonics Corp.

Samples were mounted on a sample holder made of boron nitride. The parasitic capacitance between the rear sample electrode and ground was minimized to $<1.5 \mathrm{pF}$. The sample holder was attached to the high vacuum sample heater produced by HeatWave Corp. The temperature of the samples was monitored by K-type thermocouple mounted into the sample holder. The sample holder was mounted on a rotating stage, together with a Faraday cup for measurement of the primary current, $I_{p}$ (see Fig.1).

The signals from the sample and from the collector were amplified by direct coupled fast amplifiers with the input resistance of $200 \mathrm{~kW}$ and the bandwidth limit of 10 MHz. Amplified signals were recorded by the Tektronix digitizing oscilloscope. The total yield of SEE was determined as: 


$$
\sigma=\frac{I_{p}-I_{s}}{I_{p}}
$$

The potential of the collector, $U_{c}$, was chosen in the range of $10-15 \mathrm{~V}$ depending saturation condition for each material and $E_{p}$.

After each shot, the vacuum chamber was opened and the surface of the samples was cleaned by a volatile conducting solvent with the following heating at $150-200^{\circ} \mathrm{C}$ in vacuum of about $10^{-7}$ Torr. This procedure does not provide complete removal of the surface charge, which is accumulated inside the material on the depth of several monolayers. However, repetitive measurements at the same primary energy showed the deviation of the SEE yield less than 5-10\%.

The influence of the thermal surface treatment, ${ }^{18}$ the angle of incident electrons, ${ }^{19}$ the surface roughness ${ }^{20}$ and the bounded surface charge $\mathrm{e}^{21,22}$ on the total yield of electron induced SEE should be taken into account as well. However, all these effects were neglected in the present work. This should imply some discrepancy between the actual measurements and the results of other authors.

\section{RESULTS AND DISCUSSION}

The measured curves of the total yield of SEE at energies lower than $100 \mathrm{eV}$ are presented in Fig. 2 for two materials, boron nitride and quartz, together with the results of

other authors. ${ }^{23,24}$ One can see that the present measurements of $\sigma\left(E_{p}\right)$ from $\mathrm{SiO}_{2}$ appear in good agreement with the results reported by Dionne. ${ }^{23}$ Some difference in SEE yield from boron nitride was observed between our present results and the measurements performed by of Bugeat and Koppel. ${ }^{24}$ Our results appear in between the measurements 
by Bugeat and Koppel and by Dawson ${ }^{25}$ who found for boron nitride $E_{1} \approx 50 \mathrm{eV}$. In our experiments, we used samples made of boron nitride grade HP produced by Saint Gobain Corp.

The obtained results show significant deviation of $\sigma\left(E_{p}\right)$ from the power fit. The curves of $\sigma\left(E_{p}\right)$ for different materials should cross each other at low energies of primary electrons. Moreover, $\sigma\left(E_{p}\right)$ from ceramics should have a local minimum and maximum in the low energy region, as it appears for macor (see Fig. 3).

The origin of the observed behavior of $\sigma\left(E_{p}\right)$ in low energy region should be in the increasing role of backscattered electrons. Indeed, the total yield of SEE consists of the yield of "true" secondary electrons, $\delta$, and of the coefficient of backscattering, $\rho$ :

$$
\sigma=\delta+\rho
$$

Detailed investigations of $\delta$ and $\rho$ components for several dielectric materials were performed by Fridrikhov and Shul'man. ${ }^{26}$ They showed that the coefficient of backscattering is usually growing with the decrease of $E_{p}$, while the yield of "true" secondary electrons decreases and reaches zero at energy of about the width of the potential gap between vacuum and the upper level of valent band. Therefore, the superposition of $\delta$ and $\rho$ should have a distinguishable minimum and maximum in the low energy region, which was observed for several oxides. ${ }^{27}$ Baral et al. ${ }^{28}$ also considered the role of the backscattering electrons in their model of SPT thruster.

The measured behavior of $\sigma\left(E_{p}\right)$ at low energies of primary electrons suggests a possible deviation from the power fit. In some sense, linear fit

$$
\sigma\left(E_{p}\right) \approx \sigma_{0}+\left(1-\sigma_{0}\right) \frac{E_{p}}{E_{1}},
$$


suggested by Morozov ${ }^{29}$ seems also relevant. Indeed, for macor at $E_{p}>50 \mathrm{eV}$ both power and linear fits are coincide well with the experimental data, as it illustrated by Fig. 3. Physical meaning of the linear fit is in non-zero electron backflow at $E_{p} \sim 0$, that should be reasonable for backscattering process. Parameters of both types of fits are presented in Table 1 for our data and data reported by Dionne and Jolivet and Roussel.

However, at low $E_{p}$ the behavior of $\sigma\left(E_{p}\right)$ should differ substantially from both types of fits. Moreover, the actual values of $\sigma\left(E_{p}\right)$ should obviously vary with surface conditions. Indeed, primary particles with energies of a few $\mathrm{eV}$ could involve in interaction only thin surface layer, which can have different roughness, can contain impurities and absorbed gases, can be contaminated, etc. The electron backscattering process is sensitive to these factors. The surface temperature should change $\sigma\left(E_{p}\right)$ in the low energy range as well. Thus, the actual slope of $\sigma\left(E_{p}\right)$ in the low energy region should differ also from our present should be better checked experimentally for each particular wall material and operating conditions.

\section{ACKNOWLEDGMENTS}

This work was supported by the New Jersey Commission of Science and Technology, and by the DOE under contract DE-AC02-76-CH03073. 


\section{FIGURES CAPTIONS}

Fig. 1. Experimental setup.

Fig. 2. Total yield of SEE from boron nitride and quartz at $E_{p}<100 \mathrm{eV}$. Dashed lines represent the previous measurements of SEE yield made by Dionne ${ }^{23}$ for quartz and by Bugeat and $\mathrm{Koppel}^{24}$ for boron nitride.

Fig. 3. Linear and power fits of the total yield of SEE from macor in comparing with measurements. 


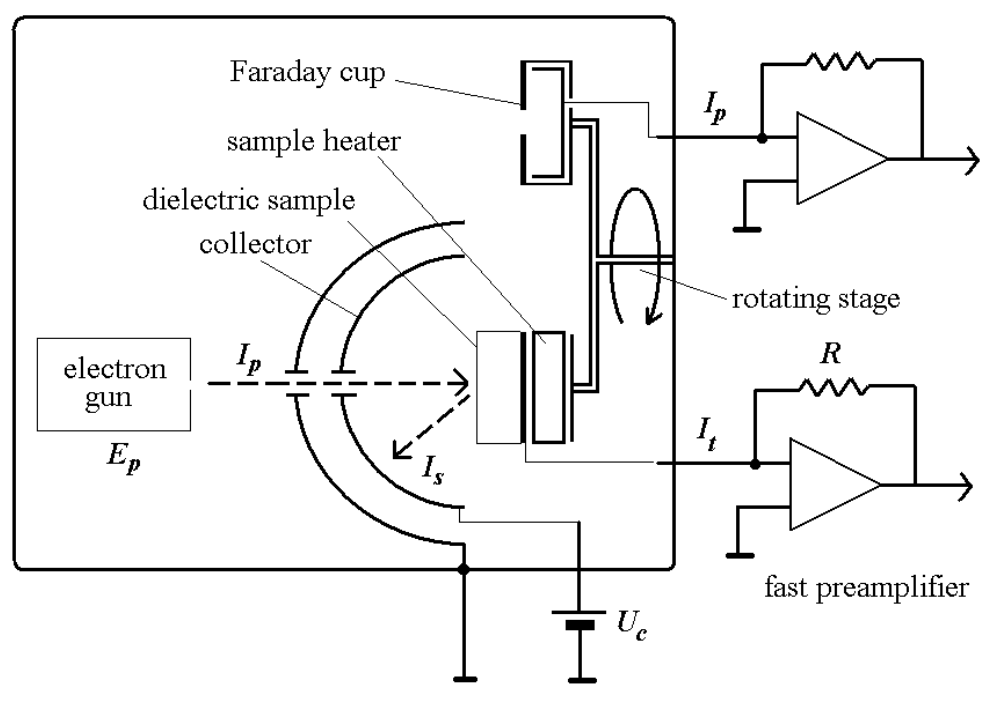

Fig. 1.

A. Dunaevsky, Y. Raitses, and N. J. Fisch, "Secondary electron emission induced by low energy electrons" 


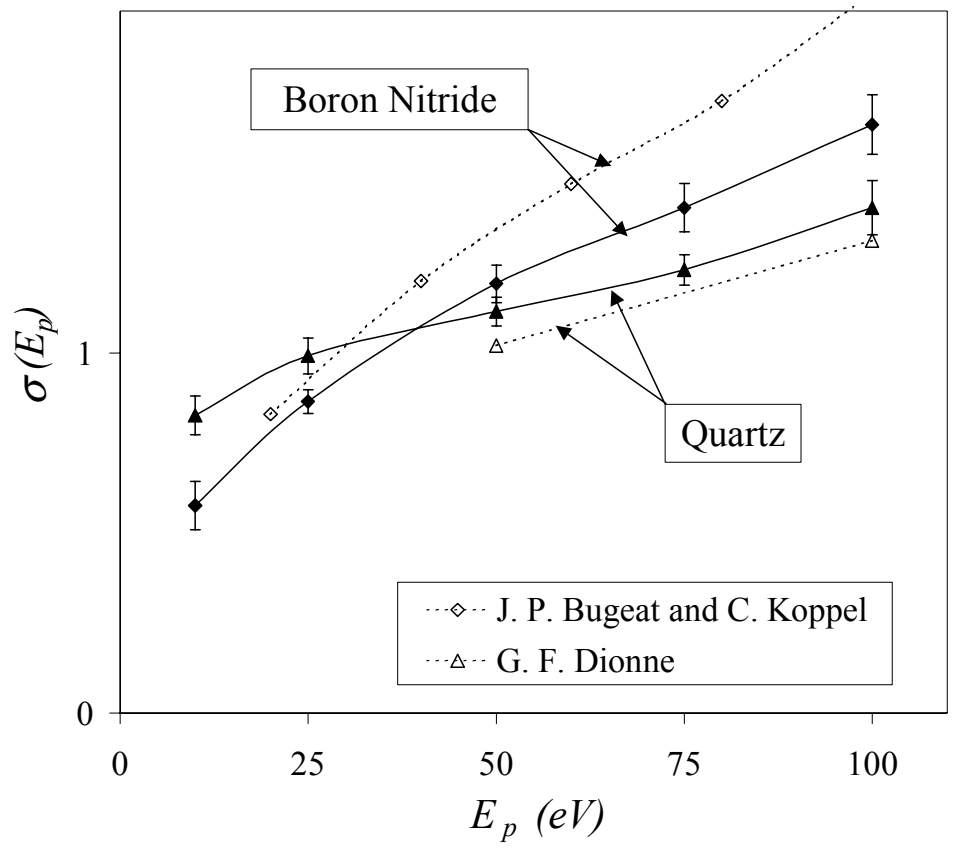

Fig. 2.

A. Dunaevsky, Y. Raitses, and N. J. Fisch, "Secondary electron emission induced by low energy electrons" 


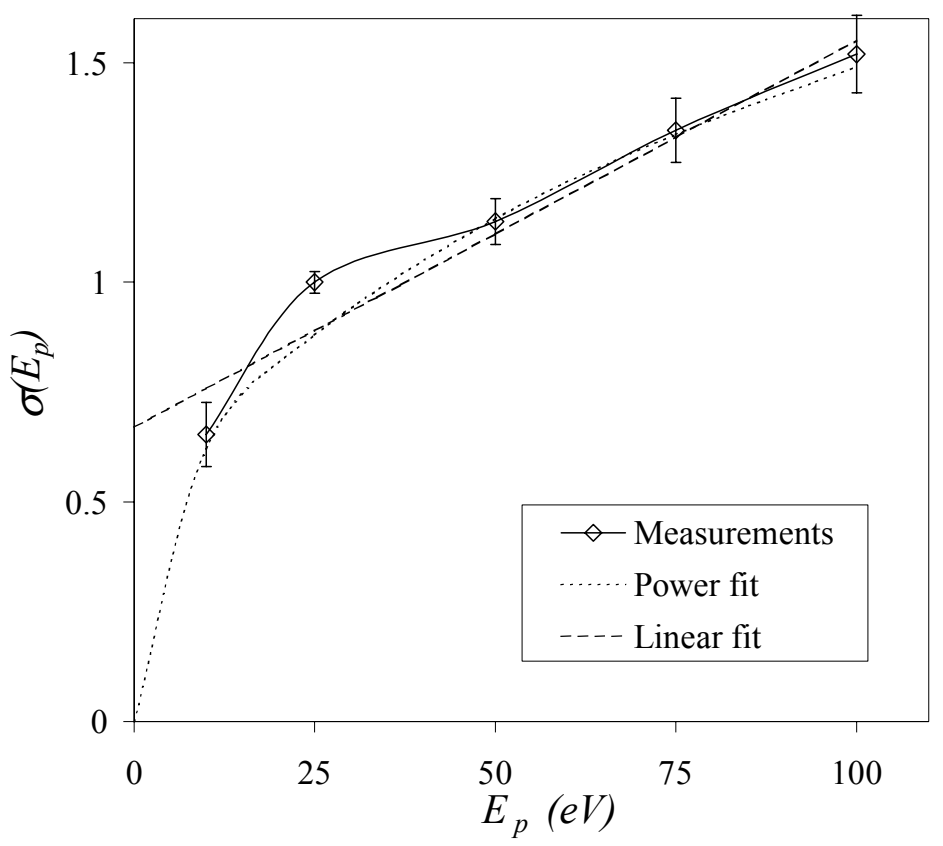

Fig. 3.

A. Dunaevsky, Y. Raitses, and N. J. Fisch, "Secondary electron emission induced by low energy electrons" 
Table 1. Parameters for linear and power fits of $\sigma\left(E_{p}\right)$ for boron nitride, macor, and quarts:

\begin{tabular}{|c||c|c|c|c||}
\hline \multirow{2}{*}{ Material } & \multicolumn{2}{c||}{ Power fit } & \multicolumn{2}{c|}{ Linear fit } \\
\cline { 2 - 5 } & $\boldsymbol{E}_{\boldsymbol{1}}$ & $\boldsymbol{\alpha}$ & $\boldsymbol{E}_{\boldsymbol{1}}$ & $\boldsymbol{\sigma}_{\boldsymbol{0}}$ \\
\hline \hline Boron Nitride (our measurements) & 35 & 0.5 & 40 & 0.54 \\
\hline Boron Nitride (Bugeat and Koppel) & 30 & 0.57 & 30 & 0.59 \\
\hline \hline Macor (our measurements) & 35 & 0.38 & 38 & 0.67 \\
\hline \hline Quartz (our measurements) & 30 & 0.26 & 35 & 0.8 \\
\hline Quartz (Dionne) & 45 & 0.32 & 45 & 0.73 \\
\hline
\end{tabular}




\section{References}

${ }^{1}$ V. V. Zhurin, R. H. Kaufman, and R. S. Robinson, Plasma Sources Sci. Technol. 8, R1 (1999).

2 E. Y. Choueiri, Phys. Plasmas 8, 5025 (2001).

${ }^{3}$ E. Ahedo, Phys. Plasmas 9, 4340 (2002).

${ }^{4}$ M. Keidar, I. D. Boyd, and I. I. Beilis, Phys. Plasmas 8, 5315 (2001).

${ }^{5}$ L. Jolivet and J.-F. Roussel, $3^{\text {rd }}$ Int. Conf. on Spacecraft Propulsion ESA/CNES, Cannes (2000).

${ }^{6}$ A. Fruchtman, N. J. Fisch, and Y. Raitses, Phys. Plasmas 8, 1048 (2001).

7 A. Fruchtman and N. J. Fisch, Phys. Plasmas 8, 56 (2001).

${ }^{8}$ Y. Raitses, J. Ashkenazy, G. Appelbaum, and M. Gualman, $25^{\text {th }}$ International Conference on Electric Propulsion, Cleveland, OH, IEPC 97-056 (1997).

9 Y. Raitses, L. A. Dorf, A. A. Litvak, and N. J. Fisch, J. Appl. Phys. 88, 1263 (2000).

${ }^{10}$ Y. Raitses, M. Keidar, D. Staack, and N. J. Fisch, J. Appl. Phys. 92, 4906 (2002).

11 N. J. Fisch, Y. Raitses, L. A. Dorf, and A. A. Litvak, J. Appl. Phys. 89, 2040 (2001).

12 G. D. Hobbs and J. A. Wesson, Plasma Physics 9, 85 (1967).

13 H. Seiler, J. Appl. Phys. 54, R1 (1983).

14 K. Kanaya, S. Ono, and F. Ishigaki, J. Phys. D: Appl. Phys. 11, 2425 (1978).

15 J. Cazaux, J. Appl. Phys. 85, 1137 (1999).

16 H. L. Hydt, Rev. Sci. Instrum. 21, 639 (1950).

17 H. von Seggern, IEEE Trans. Nucl. Sci. NS-32, 1503 (1985).

18 J. B. Johnson, Phys. Rev. 73, 1058 (1948). 
19 A. Shih and C. Hor, IEEE Trans. on Electron Devices 40, 824 (1993).

20 Y. C. Yong, J. T. L. Thong, and J. C. H. Phang, J. Appl. Phys. 84, 4543 (1998).

21 T. Sato, S. Kobayashi, S. Michizono, and Y. Saito, Applied Surface Science 144-145, 324 (1999).

22 L. L. Hatfield and E. R. Adamson, Proc. of IEEE Conf. On Electrical Insulation and Dielectric Phenomena, Arlington, TX, October 23-26, 256, (1994).

23 G. F. Dionne, J. Appl. Phys. 46, 3347 (1975).

24 J. P. Bugeat, and C. Koppel, $23^{\text {th }}$ International Conference on Electric Propulsion, IEPC 95-35 (1995).

25 P. H. Dawson, J. Appl. Phys. 37, 3644 (1966).

26 S. A. Fridrikhov and A. R. Shul'man, Sov. Phys. - Solid State 1, 1153 (1959).

27 N. P. Bazhanova, V. P. Belevskii, and S. A. Fridrikhov, Sov. Phys. - Solid State 3, 1899 (1962).

28 S. Baral, K. Makowski, Z. Perdzynski, N. Gascon, and M. Dudek, $27^{\text {th }}$ International Conference on Electric Propulsion, Pasadena, CA, IEPC 01-27 (2001).

29 A. I. Morozov, Sov. J. Plasma Phys. 17, 393 (1991). 


\section{External Distribution}

Plasma Research Laboratory, Australian National University, Australia

Professor I.R. Jones, Flinders University, Australia

Professor João Canalle, Instituto de Fisica DEQ/IF - UERJ, Brazil

Mr. Gerson O. Ludwig, Instituto Nacional de Pesquisas, Brazil

Dr. P.H. Sakanaka, Instituto Fisica, Brazil

The Librarian, Culham Laboratory, England

Mrs. S.A. Hutchinson, JET Library, England

Professor M.N. Bussac, Ecole Polytechnique, France

Librarian, Max-Planck-Institut für Plasmaphysik, Germany

Jolan Moldvai, Reports Library, MTA KFKI-ATKI, Hungary

Dr. P. Kaw, Institute for Plasma Research, India

Ms. P.J. Pathak, Librarian, Insitute for Plasma Research, India

Ms. Clelia De Palo, Associazione EURATOM-ENEA, Italy

Dr. G. Grosso, Instituto di Fisica del Plasma, Italy

Librarian, Naka Fusion Research Establishment, JAERI, Japan

Library, Plasma Physics Laboratory, Kyoto University, Japan

Research Information Center, National Institute for Fusion Science, Japan

Dr. O. Mitarai, Kyushu Tokai University, Japan

Library, Academia Sinica, Institute of Plasma Physics, People's Republic of China

Shih-Tung Tsai, Institute of Physics, Chinese Academy of Sciences, People's Republic of China

Dr. S. Mirnov, TRINITI, Troitsk, Russian Federation, Russia

Dr. V.S. Strelkov, Kurchatov Institute, Russian Federation, Russia

Professor Peter Lukac, Katedra Fyziky Plazmy MFF UK, Mlynska dolina F-2, Komenskeho Univerzita, SK-842 15 Bratislava, Slovakia

Dr. G.S. Lee, Korea Basic Science Institute, South Korea

Institute for Plasma Research, University of Maryland, USA

Librarian, Fusion Energy Division, Oak Ridge National Laboratory, USA

Librarian, Institute of Fusion Studies, University of Texas, USA

Librarian, Magnetic Fusion Program, Lawrence Livermore National Laboratory, USA

Library, General Atomics, USA

Plasma Physics Group, Fusion Energy Research Program, University of California at San Diego, USA

Plasma Physics Library, Columbia University, USA

Alkesh Punjabi, Center for Fusion Research and Training, Hampton University, USA

Dr. W.M. Stacey, Fusion Research Center, Georgia Institute of Technology, USA

Dr. John Willis, U.S. Department of Energy, Office of Fusion Energy Sciences, USA

Mr. Paul H. Wright, Indianapolis, Indiana, USA 
The Princeton Plasma Physics Laboratory is operated by Princeton University under contract with the U.S. Department of Energy.

\author{
Information Services \\ Princeton Plasma Physics Laboratory \\ P.O. Box 451 \\ Princeton, NJ 08543
}

Phone: 609-243-2750

Fax: 609-243-2751

e-mail: pppl_info@pppl.gov

Internet Address: http://www.pppl.gov 